\title{
Current legislation on heavy metals in foods and animal feeding-stuffs
}

\author{
By A. W. Hubbard and T. J. Coomes, Food Science Division, Ministry of \\ Agriculture, Fisheries and Food, London
}

Quite contrary to what is generally assumed, there is not a great deal of specific legislation on food contaminants in the UK and we rely very much on the general provisions of the Food and Drugs Act. Therefore, this paper is concerned more with the UK philosophy and how various surveillance programmes, which we are responsible for, back-up the UK philosophy.

Statutory protection is afforded by the general provisions of the Food and Drugs Act 1955. Section 1 of the Act makes it an offence to add anything to food so as to render it injurious to the health of the consumer. Section 2 requires that food is of the nature, substance, and quality demanded by the purchaser, a term which has surely stood the test of time. Section 8 makes it an offence to sell unfit food. Section 4 of the Act gives Ministers the power to make regulations to reinforce these general provisions with more specific requirements. But, the only specific regulations applying to food contaminants are the Lead in Food Regulations 1961 (Great Britain: Parliament, 196r) and amendments and the Arsenic in Food Regulations 1959 (Great Britain: Parliament, 1959) and amendments.

The impetus for these Regulations derived from serious acute poisoning episodes where food became inadvertently contaminated at high levels. These episodes involved the storage of acidic beverages in lead vessels and, in the case of arsenic, through the use of sulphuric acid to convert sucrose into glucose for brewing purposes. The sulphuric acid had been made from arsenical pyrites and was contaminated with arsenic trioxide. However, such episodes are now history.

\section{Heavy metal contamination of food}

The levels of heavy metal residues which have been found in food in recent times have only been detected by sophisticated developments in analytical methodology. Whereas ten, or even five years ago, the detectability and sensitivity of an analytical method was expressed in terms of milligrams, or micrograms, today, the nanogram and picogram are invoked with increasing frequency. Not surprisingly, the ease with which consumer concern can be aroused and both food manufacturers and regulatory authorities criticized increases with each succeeding report in a world striving unrealistically towards absolute purity. Much of this criticism may be ill-informed but regulatory authorities responsible for public health could be failing in their duty if they did not consider the implications for public health of both the contaminants themselves and levels at which these occur in food and the environment. 
Rarely, if ever, are the levels of heavy metals which can now be detected in foods such that immediate health effects are observed on ingestion. Any possible risk to health from such contaminants or residues arises from the possibility that a continuing or long-term exposure to small amounts might invoke an adverse biological response in man at some time during his normal lifespan. Such risks are classically difficult to evaluate, particularly since such effects on health can only be demonstrated by epidemiological methods. Effects, such as the impairment of neurological function are extremely difficult to demonstrate unless populations are heavily exposed and the effects can be measured by methods which are sufficiently developed to observe subtle effects in behaviour.

Heavy metals such as lead, iron, cadmium, mercury, chromium, copper and nickel, together with the metalloid, arsenic in their many compounds in nature all enter man's food chain from the soil or from water in the first instance. Since man has always been exposed to certain low levels of many of the chemical contaminants known today, a population would have to be subject to exposure at well above average levels to detect an increased incidence of a health effect. It does not follow that because only lead and arsenic have been specifically controlled by law, these are the only areas of potential hazard. It has always been recognized in the UK that the most effective protection for the consumer against any hazards arising from contaminant residues in food is a vigilant and responsible food industry. The cooperation which has existed for many years between all those involved in the food chain (from the grower or producer to the final seller) and the government, has ensured consumer protection.

Because any risks associated with the ingestion of heavy metals in food are so difficult to determine, a resort to legal limits is necessarily arbitrary. The widespread use of such controls could lead to the removal of perfectly good and wholesome foods from the market, the nutritional and other benefits of which far outweigh any risks arising from eating them, and without necessarily bringing about any reduction in the levels being found in the foods. In the UK, therefore, we have tended to operate a pragmatic approach to the control of food contaminants which might conveniently be described as 'the best practicable means' having regard to the nature of the problem. By these means we have been able, with the active cooperation of industry, to significantly reduce the exposure of the consumer to many contaminants without having to resort to specific legislation.

Exposure of the population to heavy metals in the diet can be evaluated by undertaking detailed programmes of monitoring both of individual foods and whole diets and this has been an important feature of recent government policy. The results from such programmes provide essential information: to safeguard the consumer; to reassure the public in situations where the issue has been dealt with by the media in an unfair or unbalanced way or in ways which suggest that audience attraction is the overriding concern; to assess whether or not legislative action is called for; to identify groups within a population that might be at particular risk (i.e. young children, expectant mothers, special immigrant groups, etc.) even though the average consumer is not; to assess dietary intakes of 
populations or groups to compare them with acceptable or tolerable intakes recommended by groups of experts and thus to determine the margins of safety.

Accurate information about the actual diet of the population as a whole or of individual consumers is difficult to obtain yet this profoundly affects the scientific basis on which any proposed statutory controls can be assessed and justified.

Our belief in the need for food surveillance has been reinforced by the experience we have gained since 1971, when the Steering Group on Food Surveillance was set up. The remit of the Group is to coordinate the efforts of all the many government laboratories and to liaise with other competent bodies in devising and carrying out monitoring programmes for contaminants in food. The Steering Group and its Working Parties and Sub-Groups have over the years generated a considerable body of information about contaminants in food. In my opinion our present programme is second to none in Europe. Its success owes much to the very willing cooperation we have had from individual industries and from regulatory authorities in the UK.

Perhaps not everyone is aware of the breadth of coverage of the Steering Group's present programme. It began with a detailed survey of mercury in food, as a result of reports from the USA that canned tuna fish could contain undesirably high levels of this contaminant. Stemming from this work, the Steering Group's bestknown sub-group, the Working Party on the Monitoring of Foodstuffs for Heavy Metals, has devoted a major effort to organizing detailed surveys for residues of trace heavy metals in foodstuffs. The five reports produced so far by this Working Party summarize the results of surveys on $\mathrm{Hg}, \mathrm{Pb}$ and $\mathrm{Cd}$ in the diet. (Ministry of Agriculture Fisheries and Food 1971, 1972, 1973a, 1973b, 1975). Reference to these reports will enable the reader to gain a closer understanding of the UK philosophy to the control of food contamination by heavy metals. The work of all these bodies over the last five years has generated a tremendous amount of information, and indeed, continues to do so. So what happens to this information and what value does it have for us all? In appropriate cases, the Steering Group has reported its findings to the Food Additives and Contaminants Committee. This is a group of independent experts, set up to advise Ministers, in respect of their responsibilities under the Food and Drugs Act, on all matters relating to food additives and contaminants. The Committee, in the course of its deliberations, seeks advice on medical and safety aspects from the Committee on Toxicity which is one of a group of Committees operating under the aegis of the CMO's Committee on Medical Aspects of Chemicals in Food and the Environment. The tremendous amount of information generated has been of singular benefit to these Committees in establishing a firm basis of knowledge in which they can give advice on issues of food safety and so to give assurance to consumers. Surprisingly perhaps to some cynics, this procedure has not resulted in a plethora of specific laws on food contaminants. In fact, no more statutory controls exist now than before the birth of the surveillance programmes five years ago. What we have been able to do, however, is to solve some of our problems pragmatically by the 'best practical means' approach and to have a firm body of fact with which to defend the 
policies of the UK Government both at home and abroad and, I hope, the needs of the food manufacturing industry against what is all too often emotional criticism with little if any solid basis.

One cannot discuss national legislation relating to food without some reference to our European partners, and to those guardians of the Treaty of Rome, the European Economic Commission. Indeed, one is becoming wary of mentioning a level of anything for fear it should be 'harmonized'. The majority of our EEC partners already have some specific laws setting down permissible levels of some contaminants in food. Our food exporters have to comply with these laws, which tend to differ from country to country so the reason for sensible measures of harmonization is self-evident. One would expect attempts at such harmonization to be effected by 'general' or horizontal directives rather than specific or vertical ones. The latter are more appropriate to commodity directives (e.g. fruit juices). The horizontal approach has so far been adopted for various classes of food additives (e.g. Emulsifiers and Stabilizers) and seems most appropriate for contaminants such as heavy metals, which need to be considered on an 'across-the-board' basis. The Commission already have a draft 'general' directive on deleterious substances in food but this has made very little progress: some two years have elapsed since the last meeting to discuss the draft. The basis of the draft directive is as an 'enabling' one, relating to undesirable substances in general. This enabling directive would then be followed by subordinate ones dealing with specific contaminants (e.g. $\mathrm{Hg}, \mathrm{Pb}$ ).

We will refrain from speculating about the likely attitude of the European Economic Commission to future harmonization exercises in the field of food contaminants. We would, however, express the hope that any future initiative by the EEC be preceded by an examination of the facts, so as to determine whether a need to harmonize really exists and that any consumer action will be limited to essentials. In the UK we have achieved much and this has been borne out by the vast amount of surveillance data we have so far accumulated.

\section{Heavy metal contamination of animal feeding-stuffs}

Animal feeding-stuffs are also the subject of both general and, to a limited extent, specific legislative requirements as respects heavy metal contamination.

The general requirements (virtually unchanged since feeding-stuffs legislation was first introduced in the UK in 1893) are in Section 73 of the 1970 Agriculture Act and, briefly, provide that it is an offence to sell feeding-stuffs containing any substance deleterious to the animals for which the feeding-stuffs are intended. The responsibility is therefore the sellers' to ensure the absence of such deleterious substances in the feeds they sell. However, certain defences, e.g. that the presence of a deleterious substance was the fault of someone else or that 'all reasonable precautions' had been taken against the possibility of the presence of a deleterious substance, are provided for elsewhere in the Act (Section 82). Although the Act contains provisions for the listing of substances in Regulations which were deemed 
to be deleterious no heavy metals were listed since it was felt that the general requirements exercised sufficient control.

Almost as soon as we joined the Community, our colleagues dealing with feeding-stuffs legislation were involved in discussions on a Commission proposal for a directive on undesirable substances in feeding-stuffs. The intention of this proposal was to set maximum permitted levels for these contaminants, including heavy metals, which were known (or in some cases suspected) to represent a danger to animal and human health. Since this proposal had been under discussion for some time when we joined the Community, my colleagues were almost presented with a 'fait accompli', but they did manage to persuade the other Member States to drop some of the more controversial items (for instance the original proposal suggested maximum limits for $\mathrm{Cd}$ and boron even though it was admitted that there was no evidence at the time to show that the maximum levels being proposed were the right ones, nor indeed that maximum levels needed setting in the first place).

\section{Table I. Prescribed limits for heavy metals in feeding-stuffs}

\begin{tabular}{|c|c|c|}
\hline Substances & Fceding-stuffs & $\begin{array}{l}\text { Maximum content in } \\
\mathrm{mg} / \mathrm{kg} \text { of feeding-stuffs } \\
\text { referred to a moisture } \\
\text { content of } 12 \%\end{array}$ \\
\hline \multirow[t]{5}{*}{ Arsenic } & Straight feeding-stuffs except: & 2 \\
\hline & $\begin{array}{l}\text { meal made from grass, from dried } \\
\text { lucerne, or from dried clover }\end{array}$ & 4 \\
\hline & $\begin{array}{l}\text { dried sugar beet pulp, or dried } \\
\text { molassed sugar beet pulp }\end{array}$ & 4 \\
\hline & $\begin{array}{l}\text { phosphates and feeding-stuffs } \\
\text { obtained from the processing of } \\
\text { fish or other marine animals }\end{array}$ & 10 \\
\hline & Whole feeding-stuffs & 2 \\
\hline \multirow[t]{4}{*}{ Lead } & Straight feeding-etuffs except: & 10 \\
\hline & phosphates & 30 \\
\hline & yeasts & 5 \\
\hline & Whole feeding-stuffis & 5 \\
\hline \multirow[t]{3}{*}{ Mercury } & Straight feeding-stuffs except: & 0.1 \\
\hline & $\begin{array}{l}\text { feeding-stuffs produced by the } \\
\text { processing of fish or other marine } \\
\text { animals }\end{array}$ & 0.5 \\
\hline & Whole feeding-stuffs & 0.1 \\
\hline
\end{tabular}

Eventually the UK (with some reluctance) and the other Member States agreed to the adoption of what is now the Directive on Undesirable Substances and Products in Feeding-stuffs-74/63/EEC. This Directive came into force in the UK on I October, 1976 in the form of Regulation 2(3) (b) and Schedule 3 to the Fertilizers and Feeding-stuffs (Amendment) Regulations 1976. Chapter A of that Schedule includes the heavy metals and Table 1 shows what the various maximum 
permitted levels are. Despite some misgivings concerning some of the proposed maximum levels (which, as with then general requirements mentioned earlier, are for sellers and not farmers to comply with), they seem to be working well or to put it another way, the Ministry has not heard of any major problems.

Where do we go from here? Well, there have already been suggestions that the list of heavy metals covered by the Directive should be extended. Our colleagues will, however, do their utmost to ensure that any additions are agreed only on the basis of firm evidence of potential harm to animals or humans or both. The absence of evidence that the constituents are safe should not form the basis for new regulations, and will, as always, call for the assistance of the industry, enforcement officials and the farmers to make sure that any additional rules in the field of heavy metal contamination of animal feeding-stuffs are not only necessary and right but also enforceable.

\section{REFERENCES}

Great Britain: Parliament (1959). The Arsenic in Food Regulations, 1959, S.I. No. 831; The Arsenic in Food (Amendment) Regulations, 1960, S.I. No. 2261; The Arsenic in Food (Amendment) Regulations, 1973, S.I. No. 1052.

Great Britain: Parliament (196r). The Lead in Food Regulations, 1961, S.I. No. 1931; The Lead in Food (Amendment) Regulations, 1972, S.I. No. 1843; The Lead in Food (Amendment) Regulations, 1973, S.I. No. 1053.

Ministry of Agriculture, Fisheries and Food (1971). Survey of Mercury in Food. First Report of the Working Party on the Monitoring of Foodstuffs for Mercury and other Heavy Metals. London: HMSO.

Ministry of Agriculture, Fisheries and Food (1972). Survey of Lead in Food. Second Report of the Working Party on the Monitoring of Foodstuffs for Heavy Metals. London: HMSO.

Ministry of Agriculture, Fisheries and Food (1973a). Suroey of Mercury in Food. A supplementary Report. Third Report of the Working Party on the Monitoring of Foodstuffs for Heavy Metals. London: HMSO.

Ministry of Agriculture, Fisheries and Food (1973b). Survey of Cadmium in Food. Fourth Report of the Working Party on the Monitoring of Foodstuffs for Heavy Metals. London: HMSO.

Ministry of Agriculture, Fisheries and Food (1975). Survey of Lead in Food. A Supplementary Report. Fifth Report of the Working Party on the Monitoring of Foodstuffs for Heavy Metals. London: HMSO. 